\title{
El patrimonio paleontológico en España: una necesidad de consenso sobre su gestión y marco legal
}

Juana Vegas, Graciela Delvene, Silvia Menéndez, Isabel Rábano, Ángel García-Cortés, Enrique Díaz-Martínez, Ramón Jiménez | Instituto Geológico y Minero de España

URL de la contribución <www.iaph.es/revistaph/index.php/revistaph/article/view/4189>

El patrimonio paleontológico (mueble e inmueble) es el conjunto de restos directos de organismos o de restos indirectos (resultado de su actividad biológica) que se han conservado en el registro geológico y al cual se le ha asignado un valor científico, didáctico o cultural. Los fósiles son parte del registro geológico y forman parte indudable de la naturaleza, independientemente de la cronología que tengan (DÍAZ-MARTÍNEZ; GARCÍA-CORTÉS; CARCAVILLA, 2013). No todos los fósiles son patrimonio geológico de tipo paleontológico per se, puesto que es necesario aplicar una metodología de valoración para evaluar si un yacimiento paleontológico es patrimonio o no (p. e. GARCÍA-CORTÉS; CARCAVILLA URQUI; DÍAZ-MARTÍNEZ et ál., 2014). Es necesario desarrollar una metodología propia que valore los ejemplares fósiles, o las colecciones, una vez extraídos de sus yacimientos que permita reconocerlos como patrimonio paleontológico mueble. Las administraciones con competencias en la materia no deberían asumir que "todo fósil es patrimonio" y que, en consecuencia, está sujeto a lo que dicta la legislación en vigor, porque, entre otras consecuencias indeseables, ello daría lugar a prohibiciones para los sectores de la obra pública y la minería que harían inviable sus actividades de extracción y/o movimiento de rocas sedimentarias, pues lo más frecuente es que contengan fósiles sin valor patrimonial (ya sean micro o macro).

En nuestro país, el patrimonio geológico de tipo paleontológico queda recogido en la legislación estatal en dos leyes de muy diferente naturaleza. En orden cronológico, los fósiles se mencionaron expresamente por primera vez en la Ley 16/1985 de Patrimonio Histórico Español, donde textualmente se dice que "forman parte, asimismo, de este Patrimonio [histórico] los elementos geológicos y paleontológicos relacionados con la historia del hombre y sus orígenes y antecedentes". A partir de esta ley se han transpuesto las posteriores leyes autonómicas y decretos sobre el patrimonio cultural, que en algunos casos interpretan e incluyen todo el registro fósil al remontarse al origen y antecedentes de los seres humanos en el planeta (ver tabla). 22 años después, cuando la mayoría de las comunidades autónomas (CCAA) tenían legislaciones sobre patrimonio cultural y gestionaban el patrimonio paleontológico, se promulgó la Ley 42/2007 y su modificación en la Ley 33/2015 de Patrimonio Natural y la Biodiversidad, que consideran expresamente a los fósiles como elementos geológicos que forman parte de la naturaleza. En ella el patrimonio geológico está definido como el "conjunto de recursos naturales geológicos de valor científico, cultural y/o educativo, ya sean formaciones y estructuras geológicas, formas del terreno, minerales, rocas, meteoritos, fósiles, suelos y otras manifestaciones geológicas que permiten conocer, estudiar e interpretar: a) el origen y evolución de la Tierra, b) los procesos que la han modelado, c) los climas y paisajes del pasado y presente y d) el origen y evolución de la vida". La consecuencia principal de esta dualidad legislativa es la variada manera de afrontar su reconocimiento, su gestión y su protección en el ámbito de las consejerías de medioambiente y cultura en las CCAA. Una amplia discusión sobre este tema ha sido extensamente tratada por varios autores (DÍAZ-MARTÍNEZ; GARCÍA-CORTÉS; CARCAVILLA, 2013; DÍAZ MARTÍNEZ; VEGAS; CARCAVILLA et ál., 2016; DELVENE; JIMÉNEZ; VEGAS et ál., 2016; DELVENE; VEGAS; JIMÉNEZ et ál., 2018; VEGAS; DELVENE; JIMÉNEZ et ál., 2017). 
a debate El marco legal para la protección del patrimonio paleontológico. ¿Qué pasa en tu comunidad?

COMUNIDADES Y CIU- LEGISLACIÓN RELACIONADA CON EL PATRI- FIGURAS DEPRO-
DADES AUTÓNOMAS IONIO HISTÓRICO O CULTURAL, CON IMPLICA- TECCIÓN
CIONES EN PALEONTOLOGIAA

Andalucía
Ley 14/2007, de 26 noviembre. Ley de Patrimonio Histórico de Andalucía

Decreto 379/2009, de 1 de diciembre, por el que se modifica el Decreto 4/1993, de 26 de enero, por el que se aprueba el Reglamento de Organización Administrativa del Patrimonio Histórico de Andalucía, y el Decreto 168/2003, de 17 de enero, por el que se aprueba el Reglamento de Actividades Arqueológicas

\begin{tabular}{|c|c|c|}
\hline Aragón & Ley 3/1999, de 10 marzo. Ley del Patrimonio Cultural & Zona paleontológica \\
\hline Asturias & $\begin{array}{l}\text { Ley } 1 / 2001 \text {, de } 6 \text { marzo. Normas reguladoras del Patrimo- } \\
\text { nio Cultural }\end{array}$ & $\begin{array}{l}\text { Sitio histórico, zona } \\
\text { arqueológica }\end{array}$ \\
\hline Canarias & $\begin{array}{l}\text { Ley 4/1999, de } 15 \text { marzo 1999. Ley del Patrimonio Históri- } \\
\text { co de Canarias } \\
\text { Decreto 262/2003, de } 23 \text { septiembre. Aprueba el Regla- } \\
\text { mento sobre intervenciones arqueológicas en la Comuni- } \\
\text { dad Autónoma de Canarias }\end{array}$ & $\begin{array}{l}\text { Sitio histórico, zona } \\
\text { paleontológica }\end{array}$ \\
\hline Cantabria & $\begin{array}{l}\text { Ley } 11 / 1998 \text {, de } 13 \text { octubre. Ley del Patrimonio Cultural } \\
\text { Decreto } 36 / 2001 \text {, de } 2 \text { mayo. Desarrollo parcial de Ley de } \\
\text { Cantabria 11/1998, de 13-10-1998, de Patrimonio Cultural }\end{array}$ & Monumento \\
\hline Castilla-La Mancha & $\begin{array}{l}\text { Ley } 4 / 2013 \text {, de } 16 \text { mayo. Patrimonio Cultural de Castil- } \\
\text { la-La Mancha }\end{array}$ & Zona paleontológica \\
\hline Castilla y León & $\begin{array}{l}\text { Ley } 12 / 2002, \text { de } 11 \text { julio. Ley del Patrimonio Cultural de } \\
\text { Castilla y León }\end{array}$ & $\begin{array}{l}\text { Sitio histórico, Bien de } \\
\text { interés cultural }\end{array}$ \\
\hline Cataluña & $\begin{array}{l}\text { Ley 9/1993, de } 30 \text { septiembre de patrimonio cultural } \\
\text { Decreto } 78 / 2002 \text {, de } 5 \text { marzo. Reglamento de protección } \\
\text { del patrimonio arqueológico y paleontológico } \\
\text { Decreto } 328 / 2011 \text {, de } 26 \text { abril. Creación del Consejo Na- } \\
\text { cional de Arqueología y Paleontología, y de la Comisión } \\
\text { de Investigación de Arqueología y Paleontología }\end{array}$ & Zona paleontológica \\
\hline Ceuta & No hay legislación & \\
\hline Extremadura & $\begin{array}{l}\text { Ley } 2 / 1999 \text {, de } 29 \text { marzo. Ley del Patrimonio Histórico y } \\
\text { Cultural }\end{array}$ & Zona paleontológica \\
\hline Galicia & $\begin{array}{l}\text { Ley 8/1995, de } 30 \text { octubre. Regula patrimonio cultural de } \\
\text { Galicia } \\
\text { Decreto 199/1997, de } 10 \text { julio. Regulación de la actividad } \\
\text { arqueológica }\end{array}$ & Zona paleontológica \\
\hline Illes Balears & $\begin{array}{l}\text { Ley } 12 / 1998 \text {, de } 21 \text { diciembre. Ley del Patrimonio Histórico } \\
\text { Decreto 144/2000, de } 27 \text { octubre } 2000 \text {. Aprueba el Regla- } \\
\text { mento de Intervenciones Arqueológicas y Paleontológicas }\end{array}$ & $\begin{array}{l}\text { Zona paleontológica, } \\
\text { lugar histórico }\end{array}$ \\
\hline
\end{tabular}

Monumento, conjunto histórico, sitio histórico, zona arqueológica, zona patrimonial

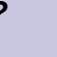


a debate El marco legal para la protección del patrimonio paleontológico. ¿Qué pasa en tu comunidad?

\begin{tabular}{|c|c|c|}
\hline La Rioja & $\begin{array}{l}\text { Ley } 7 / 2004 \text {, de } 18 \text { octubre } 2004 \text {. Normas reguladoras del } \\
\text { Patrimonio Cultural, Histórico y Artístico de La Rioja }\end{array}$ & $\begin{array}{l}\text { Zona paleontológica, } \\
\text { Monumento }\end{array}$ \\
\hline Madrid & $\begin{array}{l}\text { Ley } 3 / 2013 \text {, de } 18 \text { junio. Patrimonio Histórico de la Comu- } \\
\text { nidad de Madrid }\end{array}$ & $\begin{array}{l}\text { Zona de interés pale- } \\
\text { ontológico }\end{array}$ \\
\hline Melilla & No hay legislación & \\
\hline Murcia & $\begin{array}{l}\text { Ley 4/2007, de } 16 \text { marzo 2007. Normas reguladoras del } \\
\text { Patrimonio Cultural de la Comunidad Autónoma de la } \\
\text { Región de Murcia }\end{array}$ & Zona paleontológica \\
\hline Navarra & $\begin{array}{l}\text { Ley Foral 14/2007, de } 4 \text { abril. Ley Foral de Patrimonio de } \\
\text { Navarra }\end{array}$ & $\begin{array}{l}\text { No considera la pale- } \\
\text { ontología }\end{array}$ \\
\hline País Vasco & $\begin{array}{l}\text { Ley } 7 / 1990 \text {, de } 3 \text { julio 1990. Regulación del Patrimonio } \\
\text { Cultural Vasco } \\
\text { Decreto 341/1999, de } 5 \text { octubre 1999. Condiciones de } \\
\text { traslado, entrega y depósito de los bienes de interés } \\
\text { arqueológico y paleontológico descubiertos en el ámbito } \\
\text { territorial de la Comunidad Autónoma del País Vasco }\end{array}$ & $\begin{array}{l}\text { No define figuras de } \\
\text { protección }\end{array}$ \\
\hline Valencia & $\begin{array}{l}\text { Ley 4/1998, de } 11 \text { junio. Ley del Patrimonio Cultural Valen- } \\
\text { ciano }\end{array}$ & Zona paleontológica \\
\hline
\end{tabular}

Legislación autonómica relacionada con el patrimonio histórico o cultural, con implicaciones para la conservación del patrimonio paleontológico en España

Aunque hay comunidades autónomas que están gestionando adecuadamente el patrimonio paleontológico desde los departamentos de Cultura, el reconocimiento del patrimonio paleontológico en la nueva legislación de patrimonio natural merece un debate y una revisión por parte de las administraciones competentes en materia de patrimonio natural y cultural a todos los niveles (desde el estatal, autonómico y municipal), junto con la participación de especialistas en paleontología procedentes de asociaciones científicas, universidades y organismos de investigación. En este marco, es deseable alcanzar un consenso lo más pronto posible, que facilite las acciones oportunas para acabar con esta dualidad en la legislación española, para que se garantice la conservación y protección de este patrimonio con las mismas premisas para todas las CCAA. Entre todos, también se debe alcanzar una solución para que la gestión del patrimonio paleontológico desde las administraciones (incluyendo permisos, investigación, conservación, inventario, custodia y uso público) se realice exclusiva- mente por profesionales en paleontología. Finalmente, habrá que garantizar que, una vez investigado, el patrimonio paleontológico de tipo mueble quede custodiado en museos que cumplan con la legislación en vigor y con las reglas del ICOM (Consejo Internacional de Museos), en las que se dicta que las funciones de un museo son coleccionar, conservar, documentar, investigar, exponer y divulgar, puesto que el patrimonio paleontológico es bien común y un legado para las generaciones futuras. 
a debate El marco legal para la protección del patrimonio paleontológico. ¿Qué pasa en tu comunidad?

\section{BIBLIOGRAFÍA}

- DELVENE, G.; JIMÉNEZ, R.; VEGAS, J.; RÁBANO, I.; MENÉNDEZ, S. (2016) Del campo a la vitrina: análisis de las casuísticas entre individuos-finalidad-ubicación en relación con el patrimonio paleontológico mueble. Madrid: Instituto Geológico y Minero de España, 2016, pp. 145-151 (Cuadernos del Museo Geominero; 20)

- DELVENE, G.; VEGAS, J.; JIMÉNEZ, R.; RÁBANO, I.; MENÉNDEZ, S. (2018) From the field to the museum: analysis of groups-purposes-locations in relation to Spain's moveable palaeontological heritage. Geoheritage DOI 10.1007/s12371018-0290-3

- DÍAZ-MARTíNEZ, E.; GARCÍA-CORTÉS, A.; CARCAVILLA, L. (2013) Los fósiles son elementos geológicos y el patrimonio paleontológico es un tipo de patrimonio natural. Madrid: Instituto Geológico y Minero de España, 2013, pp. 583-589 (Serie Cuadernos del Museo Geominero, n. ${ }^{\circ} 15$ )

- DÍAZ-MARTíNEZ, E.; VEGAS, J.; CARCAVILLA, L.; GARCÍA-CORTES, A. (2016) Base conceptual, estado de la cuestión y perspectivas de la gestión y conservación del patrimonio paleontológico. Madrid: Instituto Geológico y Minero de España, 2016, pp. 159-163 (Cuadernos del Museo Geominero; 20)

- GARCÍA-CORTÉS, A.; CARCAVILLA URQUI, L.; DÍAZMARTÍNEZ, E.; VEGAS, J. (2014) Documento metodológico para la elaboración del Inventario Español de Lugares de Interés Geológico (IELIG) [disponible en línea] Instituto Geológico y Minero de España <http://www.igme.es/patrimonio/descargas. htm> [Consulta: 02/05/2018]

- VEGAS, J.; DELVENE, G.; JIMÉNEZ, R.; RÁBANO, I.; MENÉNDEZ, S. (2017) Análisis de la situación en España y propuestas para promover mecanismos para regular la recolección y controlar el comercio de elementos muebles del patrimonio geológico. Instituto Geológico y Minero de España. Informe inédito entregado al MAPAMA 